\title{
Prototype of Heat Exchanger U-Tube Model Shell and Tube Counter Flow
}

\author{
(First Project)
}

\author{
Hairil Budiarto ${ }^{1}$, Faikul Umam \\ Mechatronics Departement \\ University of Trunojoyo Madura \\ Bangkalan, Indonesia \\ ${ }^{1}$ haidar_060282@trunojoyo.ac.id
}

\begin{abstract}
This research aimed to discuss the manufacturing of The Heat Exchanger Cooler Type U-Tube with 2 types of fluid, water as cold fluid and oil as hot fluid, which flew in opposite direction. There were 2 methods which used in this research, the empirical method and the experimental method. The empirical method used some formulas to find out the impact of using $U$ Tube as a heat exchanger, while the experimental method used by taking data in real time. There were 2 different pumps used in this heat exchanger, water pump and oil pump. The average oil pump flow rate was about $9.64 \mathrm{~L} / \mathrm{min}$ and the temperature was about $95.17^{\circ} \mathrm{C}$. On the other hand, the average water pump flow rate was about $30.42 \mathrm{~L} / \mathrm{min}$ and the temperature was about $30.50^{\circ} \mathrm{C}$. The material of tubes was made of a copper tube which had $4 \mathrm{~mm}$ inner inlet diameter and $6 \mathrm{~mm}$ outer inlet diameter. There was $31 \mathrm{U}$ shaped copper tubes in total which had $1000 \mathrm{~mm}$ length for each. Based on the experimental method, it was proved that this type of heat exchanger made $58.83 \%$ of temperature dropped.
\end{abstract}

Keywords-heat exchanger; counter flow; U-Tube; fluids; cooler; flowrate

\section{INTRODUCTION}

Heat exchangers are devices that facilitate the exchange of heat between two fluids that are at different temperatures while shielding them from blending with one another. Heat transfer in a heat exchanger usually involves convection in each fluid and conduction through the wall separating the two fluids. In the analysis of heat exchangers, it is convenient to work with an overall heat transfer coefficient $U$ that accounts for the contribution of all these effects on heat transfer [3]. The rate of heat transfer between the two fluids at a location in a heat exchanger depends on the magnitude of the temperature difference at that location, which varies along the heat exchanger. Heat transfer equipment that uses fluid to another fluid is a water heater - filler - open kettle (open feed - water heater), but what is more commonly used is a heat exchanger where one fluid is separated from the other fluid by a wall or bulkhead that is passed by heat, Recuperator type heat exchangers are pipe-shaped heat exchangers in the pipe. There are various ways to increase the effectiveness of heat exchanger, according to mechanical engineering by increasing the coefficient of heat transfer of convection, increasing the surface area of the heat exchanger and increasing the temperature difference to reach the specified temperature. The second way to achieve the expected temperature quickly is to use the control method, with input fluid temperature, pomp a shell speed, cooling fan speed and expected output is the desired fluid temperature. In a heat exchanger that includes a tube bank, the tubes are generally set in a (shell-and-tube heat exchanger), particularly when the liquid is a fluid, and the liquid flow through the space between the tubes and the shell. Flow through the tubes can be dissected by thinking about move through a solitary tube, and duplicating the outcomes by the quantity of tubes. This is not the case for flow over the tubes, however, since the tubes affect the flow pattern and turbulence level downstream, and thus heat transfer to or from them. Therefore, when analyzing heat transfer from a tube bank in cross flow, we must consider all the tubes in the bundle at once.

\section{LITERATURE REVIEW}

\section{A. Previous Research}

Budiarto [1], in his research said that the variations in static twisted tape length and variations in hot oil fluid discharge has a real effect on pressure drop on counter flow oil coolers, the results of the research are the longer static twisted tape installed. in the inner tube heat exchanger and with the increasing flow of hot fluid flow, in each test with the same variation of hot oil fluid discharge will increase pressure drop, and effectiveness. The relations between static twisted tape length variation to pressure drop on the inner tube caused by static twisted tape or without static twisted tape installation on each variation of hot fluid discharge. In Fig 1 it can be seen that the pressure drop is directly proportional to the increasing length of static twisted tape and the increase in heat oil discharge. 


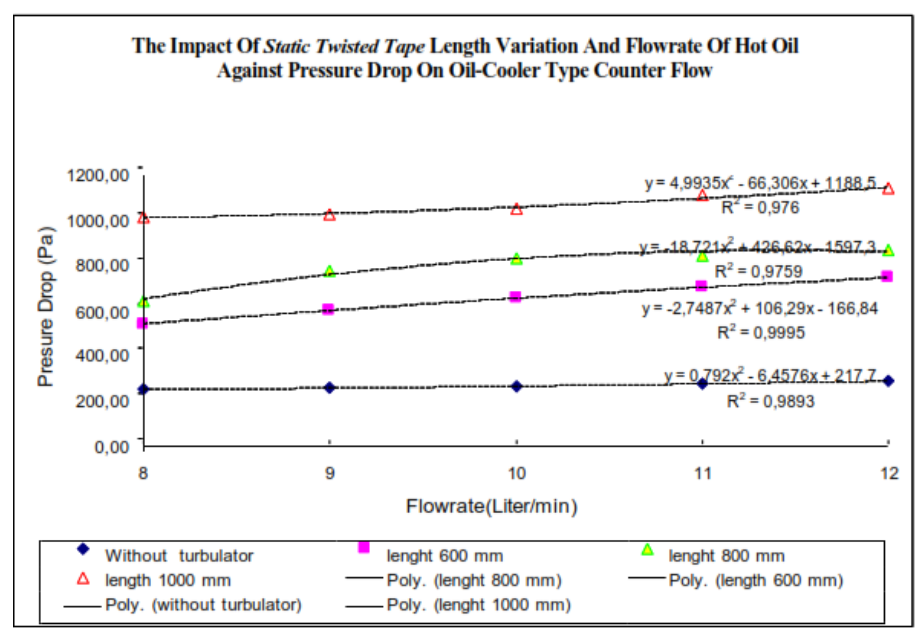

Fig. 1. Graph of the influence of the static twisted tape length variations and the effect of variations in hot oil fluid

Hidayat [10], in his seminar entitled 'Application of Fuzzy Logic to Control PID Parameter Tuning On The Setting Temperature Of The Liquid Shell And Tube Heat Excanger'. The design of its hardware uses an LM35 as a temperature sensor, DC servo motor used to drive the tap (valve), a heating (heater) and 300 watt power with an AC voltage source and a microcontroller that serves as the center of control and PC, reference testing with fixed input as shown in Fig 2 and Fig 3.

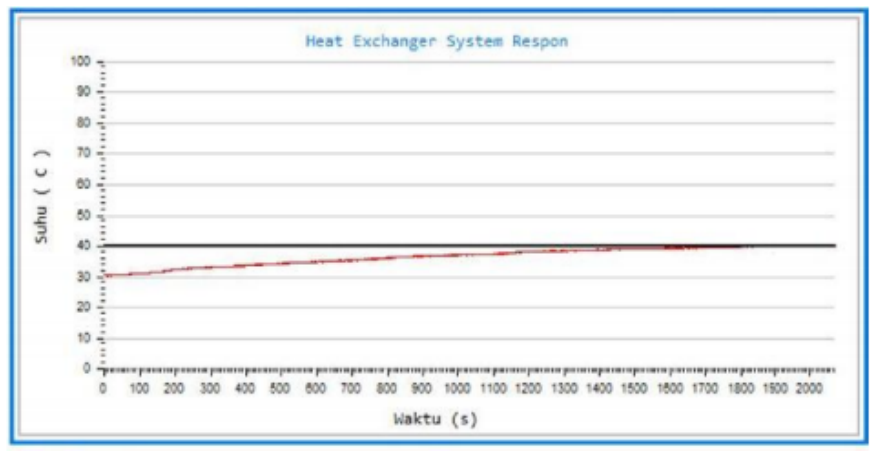

Fig. 2. System response time of Fuzzy PID method with fixed reference

Fuzzy control for tuning PID parameters can produce a good control signal so that it can produce a good response too.

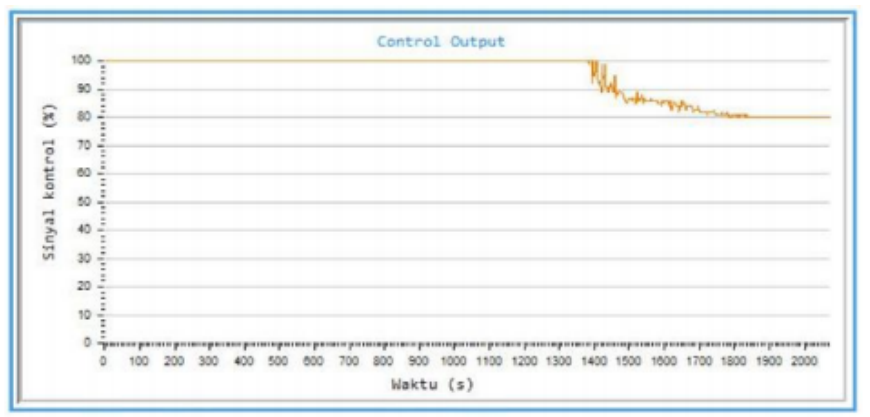

Fig. 3. Fuzzy PID output signal control with fixed reference.
In his research with fuzzy logic control, a PID parameter can corresponds to the error system, generate control signals and stable response systems, a good sensor results with a value of error about $0,08^{\circ} \mathrm{C}$, testing with set points go up or down, control signals can follow the settling points.

Ekasari [5], in his research entitled 'Controlling Fluid Temperature in Heat Exchanger Using Model Of Predictive Control (MPC) Algorithm', concluded that MPC belongs to the concept of process controller-based design concept, with the controller design results very depending on the validity of the approach model used, the most suitable MPC is to use 20 horizon predictions and 4 horizon controls and steady state time requires 70 seconds.

Control of the linear plant approach with the MPC controller can produce a stable response without overshoot and according to the set point value of $70^{\circ} \mathrm{C}$ at a fixed load or varying load of about $20 \%$ of the nominal load with a steady state of 35 seconds. Padhee [7], in his research entitled 'Controller Design For Temperature Control Of Heat Exchanger System' the focus of his research was on graphics analysis of several controller techniques that will be applied to regulate the temperature of the heat exchanger, from the simulation it was found that the internal model control has a higher performance value than feedback and feedback plus feed-forward controller methods, the implementation of using the PID controller shows a high degree of overshoot on the same setling time.
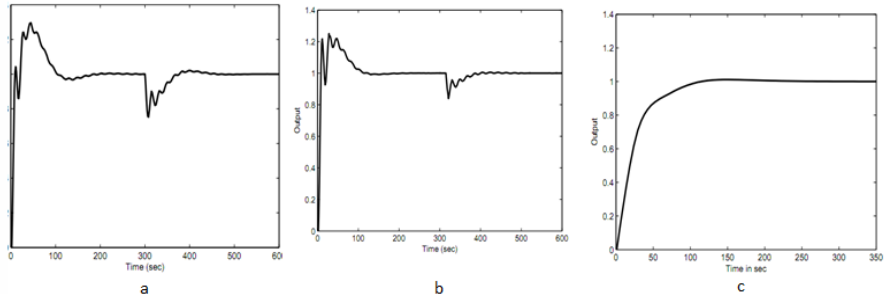

Fig. 4. Set point and load disturbance response using (a) PID controller (b) feedback plus feedforward controller (c) internal controller model.

\section{B. Basic Theory}

Heat energy is a form of energy that can be moved from one system to another system as the result of a difference in temperature. On steady flow fluid in a channel where there is one inlet and one outlet then the flow rate of a fluid mass that enters will equal the mass flow rate of the fluid in or out, or $\mathrm{mi}_{\mathrm{n}}=\mathrm{m}_{\text {out }}=\mathrm{m}$. If the liquid does not take the necessary steps then the extent of the heat energy that transfered will be equivalent to the energy change of the system, At the point when the kinetic inactive and potential energies are unimportant, which is typically the case, and there is no work interaction, the energy balance for such a steady-flow system reduces to Fig. 4. 


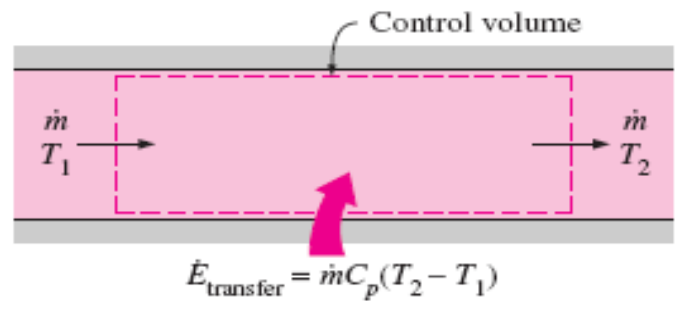

Fig. 5. Transfer of heat energy to a system with volume control

The amount of heat energy in the system can be expressed by the following equation:

$$
\dot{Q}=M C_{P} \Delta T
$$

with:

$\mathrm{Q}=$ heat energy rate

$\mathrm{M}=$ fluid mass flow rate $(\mathrm{kg} / \mathrm{s})$

$\mathrm{Cp}=$ specific heat at a constant pressure $(\mathrm{J} / \mathrm{kg})$

$\Delta \mathrm{T}=$ temperature change $\left({ }^{\circ} \mathrm{C}\right)$

Heat transfer can be defined as the transfer of energy from one system to another as a result of temperature differences, this energy transfer always occurs from a high temperature system to another system that has a lower temperature and will stop after both systems reach the same temperature, the temperature difference is the main requirement for the transfer of the system. if the two systems have the same temperature, there will be no heat transfer in the second

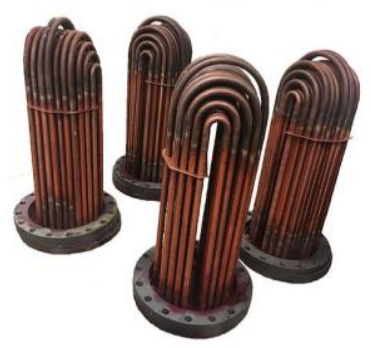

Fig. 6. Heat excanger type U-Tube

The conduction heat transfer rate was stated by J.B.J. Fourier in 1822, namely the amount of proportional heat transfer rate of heat to the surface area through heat, temperature difference, and thermal conductivity of material, but inversely proportional to the thickness of the surface traversed by heat.

$$
\dot{Q}_{\text {cond }}=-k A \frac{\left(T_{2}-T_{1}\right)}{\Delta x}
$$

Which:

$\mathrm{Q}_{\text {cond }}=$ conduction heat transfer rate $(\mathrm{W})$

$\mathrm{K} \quad=$ thermal conductivity material $\left(\mathrm{W} / \mathrm{m}{ }^{\circ} \mathrm{C}\right)$

A $=$ heat transfer surface area $\left(\mathrm{m}^{2}\right)$

$\mathrm{T} 2-\mathrm{T} 1=$ Temperature difference of heat transfer surface $\left({ }^{\circ} \mathrm{C}\right)$

$\Delta \mathrm{x} \quad=$ thickness of heat transfer surface in the axis $x(\mathrm{~m})$
Consider a fluid entering a circular tube at a uniform velocity. As in external flow, the fluid particles in the layer in contact with the surface of the tube will come to a complete stop. This layer will also cause the fluid particles in the adjacent layers to slow down gradually as a result of friction. To compensate for this velocity decrease, the velocity of the liquid at the waist of the tube should increment to keep the mass stream rate through the tube consistent. Thus, a velocity limit layer creates along the tube. The thickness of this boundary layer increases in the flow direction until the boundary layer reaches the tube center and thus fills the entire tube, as shown in Fig 7. The region from the tube inlet to the point at which the boundary layer merges at the centerline is called the hydrodynamic entrance region, and the length of this region is called the hydrodynamic entry length Lh. Flow in the entrance region is called hydrodynamically developing flow since this is the region where the velocity profile develops

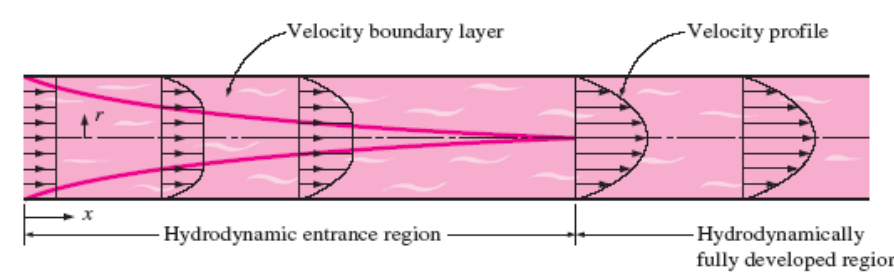

Fig. 7. Example of a Hydrodynamic limits

The locale of flow over which the thermal limit layer creates and achieves the tube center is known as the thermal entrance region, and the length of this area is known as the thermal section length (Lt). Flow in the thermal entrance region is called thermally developing flow since this is the region where the temperature profile develops. The region beyond the thermal entrance region in which the dimensionless temperature profile expressed as (Ts -T)/ (Ts$\mathrm{Tm})$ remains unchanged is called the thermally fully developed region. The area in which the flow is both thermally and hydrodynamically created and in this manner both the velocity and dimensionless temperature profiles stay unaltered is called completely developed flow.

\section{RESEARCH APPROACH}

\section{A. Prototype Design}

The prototype of heat exchanger uses two different materials for shell and tube, materials for shell tube using is acrylic pipes and for tubes is using copper, design of heat exchanger for shell pipe has an inner diameter of $256 \mathrm{~mm}$ and an outer diameter of $800 \mathrm{~mm}$, with a shell length of $1000 \mathrm{~mm}$, Whereas for the pipe tube of heat exchanger uses copper pipe with dimensions of inner diameter is $4 \mathrm{~mm}$ and outer diameter is $6.3 \mathrm{~mm}$ with tube length is $1000 \mathrm{~mm}$ 


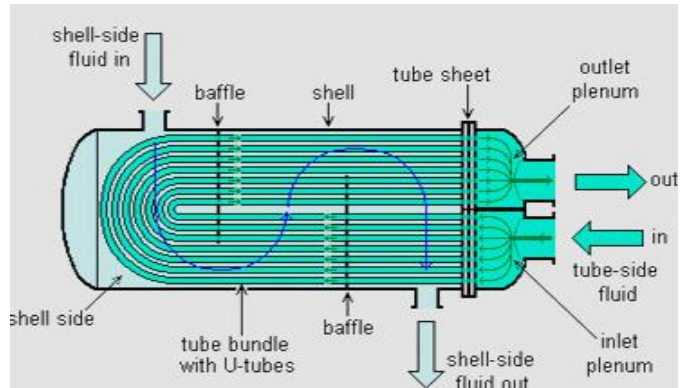

Fig. 8. U-Tube Heat Exchanger

Another supporting device is Pump, there are two types of pumps that are used: water pumps and oil pumps with different specifications. The spesification of the water pump as shown in Fig 9.

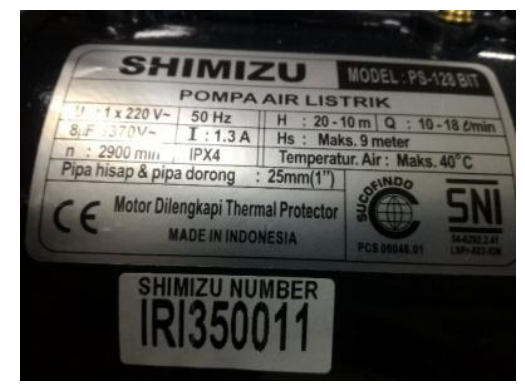

Fig. 9. Water pumps spesification is used in prototype Heat Exchangers

The dimensions of the water pump as follows:

- Shimizu pump brand

- $50 \mathrm{~Hz}$ working frequency

- Suction depth of 10-20 meters

- Height of 9 meters of water distribution

- Discharge of 10-18 liters / minute

- $40^{\circ} \mathrm{C}$ operating temperature.

The use of inlet and outlet pipes is determined by a $3 / 4$ inch pipe, the pipeline groove will be determined later by following the frame shape of the heat exchanger prototype. For the oil pump will use a modified water pump in the windmill/fan of the pump, the Windmill/ fan will use metal material so that it will not interfere with the performance of the pump itself. The spesification of the oil pump as shown in Fig. 9.

The oil pump dimensions used are:

- Brand sanyo oil pump

- 125 Watts of pump power, $220 \mathrm{~V}-50 \mathrm{~Hz}$

- 9 meter suction power

- 30 meter flow height

- Discharge of 30 liters / minute

- Maximum water temperature of $45^{\circ} \mathrm{C}$

B. Method

There are two methods used in this study i.e.:
1) Teoritical/Emprical Method: This method uses the formula to do a quantity of heat transfer that occurs in the tube, the calculation of the heat exchanger prototype analysis, determined by statistical variable:

- Discharge on water pump spcified by 10 liters/min

- Flowrate at the oil pump specified by 5 litres/ minute

- $\mathrm{T}_{\text {cold }}$, in (water-in temperature $)=25^{\circ} \mathrm{C}$.

- $\mathrm{T}_{\text {hot }}$, in ( oil-in temperature $)=60^{\circ} \mathrm{C}$.

To specify the calculation of this research are used a few formulas include:

- calculation the final temperature of the oil-out tube

$$
T_{\text {oil out }}=T_{h(\text { out })}=T_{s}-\left(T_{s}-T_{i}\right) \exp \left(-\frac{A_{s} \cdot h}{M^{o} \cdot C_{p}}\right)
$$

\section{PRACTICAL/ACTUAL METHOD}

Practical/actual method is retrieving data from a device that is read by sensors installed around the tube, the data that will be taken is the data from the the temprature sensor and flowrate sensor.

\section{RESULT}

The process of making a Heat Exchanger with a U-tube shape requires some materials and tools, the tube bending technique requires more concentration, if it carelessly causes the copper pipe (tube) to be deformed so the diameter will narrow which will result in clogging of hot fluid flow in the form of oil, and cause oil flow discharge cannot be controlled. The worst damage can cause oil pump performance cannot be maximal. The making of shell and U-tube is made in the Mechatronics Laboratory of Trunojoyo University of Madura shown on Fig. 11.

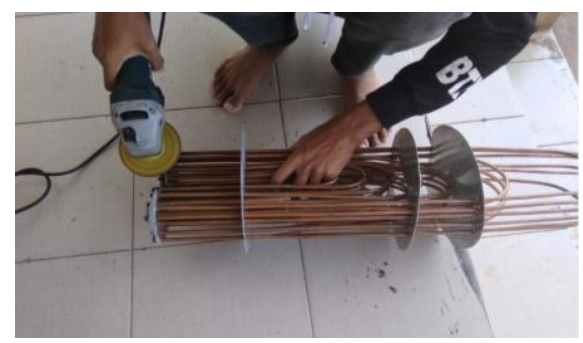

Fig. 10. Building Process of U-Tube Model

The resulting $U$ tube shape is not symmetrical, because the $\mathrm{U}$ tube combat area is forced to be the same as the linear $\mathrm{U}$ tube shape. The $U$ tube area must be the same to be able to compare the test results between the heat exchanger in the form of linear $U$ tube and $U$ tube.

The next process is the installation of the tube into the shell, and test the shell leak or $U$ tube that has been made. If the shell and $U$ tube are suitable, the installation of the Heat Exchanger prototype has been made, laying the shell and $U$ tube, as in Fig. 11. 


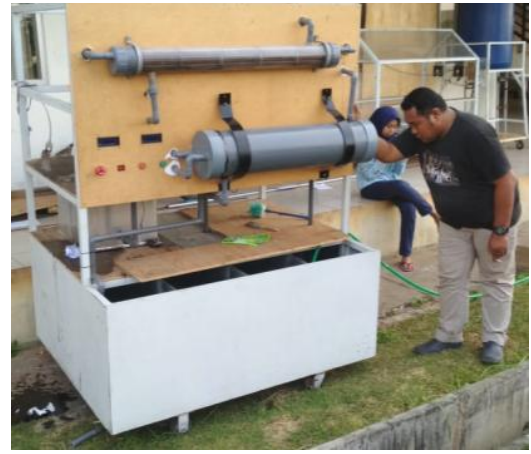

Fig. 11. Installing the shell and U tube

The next step is to do mechanical testing and calculation. As in previous studies with the linear form of shell and tube, two data will be generated, namely Empirical data and Actual data.

Empirical data, is a mechanical calculation data by following the heat transfer step according to the material used. Actual data is data generated from the device directed, recorded and presented in the form of tables. Empirical data calculations, are determined by specifying numbers:

- The discharge at the water pump is determined by 30 liters / minute

- The discharge at the oil pump is determined to be 9 liters / minute

- T-cold (inlet water temperature) $=29^{\circ} \mathrm{C}$.

- $\mathrm{T}$-hot (inlet oil temperature) $=100{ }^{\circ} \mathrm{C}$

Actual data is data recorded from sensor output that has been installed on the prototype heat exchanger, there are sensors and actuators installed are:

- Temperature sensor for water-in

- Temperature sensor for water-out

- Temperature sensor for oil in

- The temperature sensor for the exit

- Flow sensor for water-in

- Flow sensor for oil in

- DC motor valve to regulate the incoming water faucet

- DC motor valve to adjust the oil valve in

The results of the data record process are carried out as in Table I and Table II.

TABLE I. ACTUAL WATER DATA

\begin{tabular}{|c|c|c|c|}
\hline $\begin{array}{c}\text { Flowrate } \\
(\mathbf{L} / \mathbf{m i n})\end{array}$ & $\begin{array}{c}\text { Water } \\
\text { Passed/mL }\end{array}$ & $\begin{array}{c}\text { Water-in } \\
\left({ }^{\circ} \mathbf{C}\right)\end{array}$ & $\begin{array}{c}\text { Water- } \\
\text { out }\left({ }^{\circ} \mathbf{C}\right)\end{array}$ \\
\hline 22.35 & 372 & 29.33 & 31.88 \\
\hline 29.79 & 868 & 30.79 & 32.15 \\
\hline 30.55 & 1377 & 30.75 & 32.27 \\
\hline 30.55 & 1886 & 30.76 & 32.79 \\
\hline 30.58 & 3907 & 30.76 & 32.76 \\
\hline 30.76 & 7492 & 31.13 & 35.16 \\
\hline 30.98 & 8008 & 30.76 & 33.30 \\
\hline 30.76 & 9545 & 31.71 & 32.30 \\
\hline
\end{tabular}

\begin{tabular}{|c|c|c|c|}
\hline $\begin{array}{c}\text { Flowrate } \\
(\mathbf{L} / \mathbf{m i n})\end{array}$ & $\begin{array}{c}\text { Water } \\
\text { Passed/mL }\end{array}$ & $\begin{array}{c}\text { Water-in } \\
\left({ }^{\circ} \mathbf{C}\right)\end{array}$ & $\begin{array}{c}\text { Water- } \\
\text { out }\left({ }^{\circ} \mathbf{C}\right)\end{array}$ \\
\hline 30.76 & 10057 & 30.76 & 32.76 \\
\hline 30.98 & 12124 & 30.76 & 32.76 \\
\hline 31.01 & 13668 & 30.27 & 32.79 \\
\hline 31.19 & 15738 & 30.76 & 31.25 \\
\hline 31.19 & 17288 & 29.79 & 33.20 \\
\hline 31.01 & 18838 & 31.23 & 33.11 \\
\hline 30.98 & 19354 & 30.76 & 31.74 \\
\hline 30.98 & 20384 & 30.62 & 32.48 \\
\hline 30.98 & 20900 & 30.27 & 33.20 \\
\hline 30.98 & 22447 & 30.27 & 32.23 \\
\hline 30.98 & 23989 & 29.30 & 33.32 \\
\hline 30.98 & 23989 & 29.30 & 33.32 \\
\hline \multicolumn{4}{|c|}{ AVARAGE } \\
\hline 30.42 & 30.50 & 32.74 \\
\hline
\end{tabular}

TABLE II.

ACTUAL OIL DATA

\begin{tabular}{|c|c|c|c|}
\hline $\begin{array}{c}\text { Flowrate } \\
\text { (L/min) }\end{array}$ & $\begin{array}{c}\text { Water } \\
\text { passed }(\mathbf{m L})\end{array}$ & $\begin{array}{c}\text { Oil-in } \\
\left({ }^{\circ} \mathrm{C}\right)\end{array}$ & Oil-out $\left({ }^{\circ} \mathrm{C}\right)$ \\
\hline 7.94 & 203 & 100.10 & 36.62 \\
\hline 8.83 & 350 & 99.12 & 36.62 \\
\hline 8.83 & 497 & 94.24 & 36.13 \\
\hline 9.27 & 651 & 97.66 & 38.09 \\
\hline 9.27 & 805 & 94.73 & 32.23 \\
\hline 9.47 & 962 & 93.26 & 36.62 \\
\hline 9.70 & 1123 & 95.21 & 36.13 \\
\hline 9.70 & 1284 & 90.82 & 37.60 \\
\hline 9.91 & 1449 & 94.24 & 37.11 \\
\hline 10.13 & 1617 & 94.73 & 36.62 \\
\hline 10.10 & 1785 & 92.77 & 38.09 \\
\hline 9.90 & 1949 & 92.77 & 39.55 \\
\hline 10.13 & 2117 & 94.24 & 38.57 \\
\hline 10.11 & 2285 & 92.77 & 39.06 \\
\hline 10.12 & 2453 & 97.17 & 38.57 \\
\hline 10.11 & 2621 & 96.19 & 39.55 \\
\hline 9.90 & 2785 & 92.77 & 40.53 \\
\hline 9.91 & 2950 & 98.14 & 41.50 \\
\hline 9.70 & 3111 & 97.17 & 41.99 \\
\hline 9.70 & 3272 & 95.21 & 41.99 \\
\hline \multicolumn{4}{|c|}{ AVARAGE } \\
\hline 9.64 & 1713,45 & 95.17 & 36.34 \\
\hline
\end{tabular}

Based on Table I and Table II, the prototype of Heat Exchanger U-Tube model shows a decrease in oil temperature, so, heat transfer is proven to come out of U-tube into the incoming water as a cooler.

The next step is empirical data, namely the calculation of mechanical heat transfer data and heat transfer from U-tube with copper material.

\section{CONCLUSION}

Based on the results of testing and discussion of Prototype of Heat Exchanger U-Tube Model Shell and Tube Counter Flow there are some conclusions can be formulated as follows:

1. The prototype heat exchanger uses two different materials for shell and tube, materials for shell tube using is acrylic pipes and for tubes is using copper. 
2. Based on the result of this project we can solved that the temprature drop on oil tube was occured. Which $\mathrm{T}_{\text {oil in }}$ was $95.17^{\circ} \mathrm{C}$ to $\mathrm{T}_{\text {oil out }}$ was $36.34^{\circ} \mathrm{C}$ or we can conclude that the temprature drop is about $58.83 \%$, Meanwhile, the water temprature raising until $2.24 \%$ due to heat transfer from hot oil to water.

3. In this paper only taken sample from practical method and actual data from the device, for the second method (empiracal methode which is the calculation of heat transfer using some formula) will be describe and compare the result of this reasearch using practical method and empirical method

\section{REFRENCES}

[1] H. Budiarto, "The Impact Of Static Twisted Tape Lenght Against Pressure Drop in Oil Cooler Type Of Counter Flow," unpublished.

[2] H. Budiarto, "Prototype of Heat Exchanger Cooler Type Shell And Tube Counter Flow Model as A Trainer for Temperature using Neuro-Fuzzy Control (ANFIS) first project,” Int. J. of Eng. Res. and Technol., vol. 6, pp. 155-160, 2017.

[3] Y.A. Cengel, Heat Transfer A Practical Approach, New York: McGraw Hill Companies, 2003.

[4] Y.A. Cengel, Fundamentals of Thermal-Fluid Sciences, New York: McGraw Hill Companies, 2001.

[5] F. Ekasari, "Pengendali Temperatur Fluida Pada Heat Excanger Dengan Menggunakan Algoritma Model Predictive Control (MPC)," J. Tek. POMITS, vol. 3, pp. 134-139, 2014.

[6] Incropera, D. Witt, Bergman, and Lavine, Fundamental of Heat and Mass Transfer, 6th ed., New Jersey: Wiley, 2007.

[7] S. Padhee, "Controller Design For Temperature Control Of Heat Excanger System: Simulation Studies," Wseas Trans. On Syst. And Control, vol. 9, pp. 485-491, 2014.

[8] R. Syahputra, "Simulasi Pengendalian Temperatur Pada Heat Excanger Menggunakan Teknik Neuro-Fuzzy Adaptif," J. Teknol., vol. 8, pp. 161168, 2015.

[9] A. Fahruddin, "Pengaruh Variasi Diameter Kawat Helical Turbulator danVariasi Debit Fluida Pendingin Terhadap Laju Perpindahan Kalor Dan Pressure Drop Pada Heat Exchanger”, unpublished.

[10] R. Hidayat, "Application Of Fuzzy Logic To Control PID Parameter Tuning On The Setting Temperature Of The Liquid Shell And Tube Heat Excanger," unpublished. 